\title{
1 The Politics of Educational Transfers: Process, Causes and Agents
}

Language planning involves a constant negotiation of the interests of different social groups and of the changing priorities of a community. Rather than treating them as a problem for policy formation, we should think of tensions as opening up more complex orientations to language in education.

Suresh Canagarajah, 2005b: 194

This chapter examines the politics of ELT educational transfers around the world in order to identify the most common variables associated with the process (what and how), causes (why) and agents (who) of ELT educational transfers worldwide. It is meant to offer the reader a global perspective, before narrowing down the focus on the politics of educational transfers in post-revolutionary Iran, the subject nation of this book. In doing so, we will propose a threefold framework: national forces and educational transfers, subnational forces and educational transfers, and supranational forces and educational transfers. Through this framework, we will use the multilevel analytical lens proposed in the introduction as a springboard to shed light on various issues surrounding the global import/export of ELT models and standards around the globe.

\section{National Forces and Educational Transfers}

One set of powerful actors in almost all nations is politicians and government officials or those who are interacting at the nation-state level. In the field of comparative policy, the term 'emulation' refers to a policy process in 
which politicians or state officials copy policy lessons taken from elsewhere (Bennett, 1991). In other words, politicians and top governmental officials are the ones who trigger a policy transfer. In the context of comparative education, 'policy borrowing' refers to a process by which education models, ideas, norms or standards are taken from one context and transplanted into another by politicians (Phillips, 2000, 2004; Phillips \& Ochs, 2003; Steiner-Khamsi, 2004). Policy emulation or borrowing is by no means a novel phenomenon. From the beginning of their existence, as noted by Siegel and Weinberg (1977), nations have sought to borrow and adapt successful policies, models and lessons from other nations, be it in the field of economy, politics, the cultural arena or in education. What is new and unprecedented, however, is the intensification and acceleration of policy borrowing nearly everywhere in the world and in nearly every field of activity, particularly in education and its sub-field of ELT.

Before examining the causes of receptiveness towards foreign lessons and ideas - labeled as 'externalization' by Schriewer (2004) - on the part of politicians, we should begin by posing a number of questions, as suggested by Steiner-Khamsi (2004): Why do politicians seek to borrow an education model from elsewhere? What are the stimuli triggering lesson drawing? What problems do politicians believe would be solved by borrowing a foreign model? David Phillips (2000, 2004; Phillips \& Ochs, 2003), one of the first scholars to pioneer research into the politics of educational borrowing, proposes various stimuli that may spark off cross-national policy attraction. Such stimuli could be economic motivations, political change or systematic collapse, internal dissatisfaction, negative external evaluation, or new configuration or allies, among others. Whatever the catalyst for change may be, it will create conditions that make possible the search for successful lessons, ideas or norms from elsewhere.

\section{Economic motives}

A major contributor to policy borrowing in the realm of education is the economic motive. Politicians and state officials often tend to perceive education as a main means to achieve economic growth and development. Such market-oriented perception towards education can be traced back to 1971, when Shultz proposed his neoliberal economic theory of human capital. The underlying assumption of his theory is the idea that the most efficient path to the national development of any society lies in the improvement of its labor force or its human capital. One way to improve human capital is to invest in education, as it increases productivity by teaching young people new skills, on the one hand, and contributes to 'development' and 'modernity' 
through the inculcation of so-called modern attitudes, on the other hand (Shultz, 1971). The human capital theory has provided a basic justification for underdeveloped and developing nations to look abroad to emulate a promising educational model that would lead them to economic growth.

The discourse accompanying English language, like that of education, equates language learning with economic and social progress and prosperity. English is represented as the language of global commerce, trade and culture. It is claimed to be inherently beneficial, holding out promises of social and economic development to all those who learn it (Barber, 1993; Crystal, 1997; David \& Govindasamy, 2005; McArthur, 1998). It is also considered key to improving social life for underdeveloped nations because it provides equal opportunity for all. Unraveling the "myth of English as an international language', Pennycook (2004) provides an excerpt from the EL Gazette, which even goes one step further by suggesting that the widespread introduction of English into primary sectors around the world will eventually lead to the amelioration of worldwide poverty.

Today, the outlook most countries in the world are creating for themselves is shaped by global interaction, the global economy, the global job market, etc. What makes English pedagogy important to most politicians is the very vital role it plays in the virtually borderless world of today, giving the language a high economic value. As a result, many fast-developing nations such as Hong Kong, Singapore, Taiwan, the Philippines, Thailand and Malaysia, among many others, have placed a high premium on English language education (see David \& Govindasamy, 2005; Gill, 2005; Pennycook, 1998; Rubdy, 2005). It is not surprising then to see that in 2002, after a gap of 20 years, Malaysian politicians and language planners revitalized the policy of English as the language of instruction in selected fields - the very policy that Malaysian politicians had seriously fought against since the independence of their nation in 1957 (Gill, 2005). In order for this goal to materialize, the Malaysian leaders and language planners constantly linked English to economic growth and development. As a result, in 2002 English was chosen to be the only language of instruction in math and science at school level. This change of language policy was soon accompanied by a change in the school curricula, for which there was a need both to borrow a model from abroad and to rely on foreign experts and consultants, most particularly from English-speaking nations (David \& Govindasamy, 2005). Hence, an economic motive was one of the reasons that led Malaysian politicians to revise their school language policy and to look abroad for a promising English education model to emulate. The question as to whether the new ELT model would lead developing nations to achieve their desired goals is an open-ended question, but one that is worth exploring. 


\section{Radical socio-economic changes}

Another stimulus that could trigger a borrowing attraction on the part of politicians might be radical socio-economic changes in a country. Since the 1970s, for example, Saudi Arabia has profoundly invested in English language education. The main factor influencing the status and function of English was the Saudi's oil boom economy. The shortage of Saudi manpower in various professional domains has resulted in the necessity to import foreign manpower, whose language of communication is English. Examining the status of English in Saudi Arabia, Al-Haq and Samadi (1996) maintain that the Saudi politicians felt a need for English in order to cope with the country's radical socio-economic changes. The authors go further to argue that in Saudi Arabia the need to borrow ELT models and standards from abroad was not imposed by forces external to the country. Rather, it was shaped by the radical changes that took place within the socio-economic context of the nation since the early 1970s.

Saudi Arabia is not the only country in which politicians and policymakers displayed enormous interest towards English due to socio-economic transformation. In fact, other oil-producing nations in the Middle East, such as Qatar and the United Arab Emirates (Karmani, 2005), can fall into this category. With the inflow of petroleum dollars, these nations have undertaken massive modernization movements since the late 1970s. These reform movements, in turn, have led to an extreme reliance on foreign expertise and human resources, mostly from Western nations. It was within this milieu that English became a powerful tool in facilitating the economic and social modernization process.

\section{Political motives}

Another major cause for educational transfers is the political motive. Sometimes foreign-borrowed policies, models or reform movements reinforce the legitimization for a fundamental reform within the nation (Schriewer, 2004; Steiner-Khamsi, 2004). In the late 1970s, after being isolated for several decades from the outside world, the Chinese government felt a need for a major reform, which would lead the nation towards openness to the outside world and modernization. An independent, creative and productive labor force became the priority for Chinese officials, so education was the first sphere targeted for modernization (Ouyang, 2003). Comparative educationalists argue (Luschei, 2004; Phillips, 2004; Steiner-Khamsi \& Quist, 2000), that when it comes to policy borrowing, politicians first search for policy solutions in their own past, and if an organization's policy legacy is not strong enough 
to solve the current problems, they look abroad for answers. Since the Chinese homegrown education models were highly contested at home, Chinese politicians displayed an enormous interest in foreign education systems. As a result, they carried out a national campaign for reforming the curriculum towards a more Western-style liberal pedagogy. In such circumstances, English education received particular attention. To speed up the reform process, Chinese politicians borrowed the CLT model from Britain, the United States, Australia and Canada, and invited foreign consultants to demonstrate 'advanced' CLT to local practitioners (Ouyang, 2003).

However, politicians do not always make carefully measured and judged decisions when it comes to borrowing a model from abroad. They may borrow a model not meant to be fully implemented locally but rather to be used as a mechanism to meet their own immediate needs. This type of policy borrowing is known as 'quick fix' or 'phony' policies (Phillips, 2004). The implementation of CLT in China could be taken as an instance of a phony policy. Ouyang (2003) maintains that Chinese officials used CLT as a catchphrase to fulfill the political target of legitimizing the need for reform at home.

In other instances, especially after a regime change, policies borrowed from abroad are used to discredit the former regime and to justify a replacement of bureaucratic functionaries (Schriewer \& Martinez, 2004). We can trace instances of such policies in most post-Soviet countries. Examining the history of English in post-Soviet Russia, Ter-Minasova (2005) maintains that the newly elected Russian officials showed an enormous interest in English education and adopted a wholesale borrowing strategy, using English as a buzzword to discredit the Soviet regime and to legitimize the need for reform, which included openness towards the outside world. Subsequently, British publishers flooded Russia with ELT textbooks, many of which were poor in quality. After some time, however, the new generation of Russian politicians took a more moderate approach by asking local publishing agencies to design English textbooks relevant to Russian culture and life.

A radical political change within a country does not always boost policy borrowing or trigger receptiveness towards foreign influence. Steiner-Khamsi (2004) argues that, during the period of regime change, politicians may either drop their references to lessons from abroad or use them in a disparaging manner to distance themselves from foreign influence. Illuminating instances of hostility towards foreign influence could be seen in the case of English education in post-revolutionary Cuba (Corona \& Garcia, 1996) and post-revolutionary Iran (Borjian, 2009). In the introductory years of these revolutions, the politicians of both nations put enormous efforts into eliminating all ties with the United States. English was the first sphere targeted for indigenization and liberation from American influence. Nonetheless, such liberalization came to an end after 
two decades. Since the early 1980s and mid-1990s, respectively, Cuban and Iranian politicians have recognized the importance of English and thus have tolerated the publication of pirated foreign-produced English textbooks, most of them American and British, in their countries.

\section{Negative internal evaluations}

Politicians often compare their education systems to those of others. Gita Steiner-Khamsi (2003) outlines three types of reaction as the result of such a comparison: scandalization, i.e. when politicians highlight the weakness of their own educational system; glorification, i.e. when politicians only highlight the strength of their own educational system, and indifference, i.e. when no reaction is displayed. While scandalization intensifies policy borrowing, glorification stimulates policy lending.

Highlighting the weakness of one's own educational system in order to underpin educational reforms is evident in much of the literature of ELT. The Malaysian government, as previously discussed, used scandalization as their main strategy to revitalize the policy of English as the language of instruction in selected fields. Entirely disregarding the role of other variables, Malaysian officials and language planners constantly blamed their education system for producing students with low English proficiency, leading the nation to underdevelopment and Malay students to unemployment (David \& Govindasamy, 2005; Gill, 2005). A similar trend of scandalization appeared in Kenya and Uganda, two former colonies of Britain, in the early 1990s. In spite of tremendous investment put into the promotion of English, fear of 'falling standards' of English was a major issue in Kenyan and Ugandan government reports and media. According to Mazrui and Mazrui (1998), a major recurrent issue in the debate was how the problem of the quality of English was leading to poor performance in other subjects, giving the impression that virtually the whole education system of Kenya and Uganda was in crisis and that the only possible way to save the situation was to invest immensely more resources into raising students' English proficiency. To solve the problem, Kenyan and Ugandan officials turned to the British Overseas Development Agency and the British Council for support. Soon a chain of projects intended to strengthen the position of English were initiated and implemented in both nations.

The reaction of 'indifference' can best be seen on the part of post-revolutionary nations, including China (Ouyang, 2003), Cuba (Corona \& Garcia, 1996) and Iran (Borjian, 2009). In spite of the existence of various negative internal and external evaluations, the politicians of these nations seem to have decided not to borrow an education model from abroad, at least in the introductory years of the three revolutions, for political and ideological reasons alone. 
We have distilled various stimuli that may spark off an attraction towards borrowing a foreign education model, lesson or idea on the part of politicians and government officials. These stimuli are by no mean conclusive, and many others can be added to the list. However, as these instances illustrate, politicians are a major force in reinforcing educational transfers for which they may have different motives, including political and economic ones.

\section{Subnational Forces and Educational Transfers}

Educational transfers cannot be examined by primarily looking at the actions of top government officials or national forces. In fact, as the insights of policy analysts (Howlett \& Ramesh, 1995; Sabatier \& Jenkins-Smith, 1993) show us, it would be misleading to refer to those in positions of authority as the sole decision makers because many other people and social forces may influence policy outcomes. In the previous section we discussed the role of politicians and national forces in reinforcing educational transfers. In this section, we seek to identify the role of subnational forces, those societal actors who interact below the nation-state level - actors who do not hold governmental authority but who use their funds, power and/or voices to pull policy outcome, either directly or indirectly, in the directions they desire.

\section{Professional elite networks}

A major subnational force involved in educational transfers is the "professional or elite networks', using Bennett's suggested (1991) term, corresponding to the 'professional tribalism' of Rose (1993). Professional networks refer to a group of connected individuals from a given profession such as TESOL and applied linguistics in the field of ELT. Having many professional concerns in common, through publishing, speech making and conferences, professional groups share ideas, expertise and information about a common problem with their transnational counterparts. 'Transfer in this sense', as Bennett (1991) notes, 'results from the existence of shared ideas among a relatively coherent and enduring network of elites engaging in regular interaction at the transnational level' (Bennett, 1991: 224).

As we will show in this book, in spite of Iranian politicians' 30 -year-long efforts to indigenize the field of ELT in the country, the 'indigenization' movement has failed to isolate local English professors and scholars from their transnational counterparts. Examining the content of the two Iranian ELT journals, we will illustrate how Iranian ELT professional networks not only discuss similar research problems with their transnational counterparts 
but also interact with them closely. The Iranian ELT journals seem to be one venue for the importation of ELT standards into the country. But can the Iranian professional ELT networks be perceived as helpless victims manipulated by their international counterparts? The answer seems to be negative as the borrowing process is happening quite willingly and voluntarily on their part. It is partly due to the fact of belonging to one transnational professional network, namely TESOL and applied linguistics, and consequently sharing similar ideas, expertise and information about issues surrounding ELT. In addition, they constantly refer to English as the 'global language of science, technology and research' in their academic discourse in order to question the product-oriented promotion of English supported by the country's politicians, and thus they are using foreign lessons as a means to legitimize the need for reform and to argue against policy decisions at home.

There are other motivations involved in supporting the idea of educational transfers on the part of professional elites. Sometimes professional networks may support educational transfers just as a mechanism to meet their own needs (Silova, 2004). Examining the motives of the local ELT stakeholders in collaborating with British experts on an exported ELT project in India, Holliday (2005) narrows his focus to a particular project, exported from Britain to Pune University in the mid-1990s. The project was intended to remodel the university's ELT curriculum and replace it with a new curriculum borrowed from the United Kingdom. While the local ELT stakeholders were aware of the so-called 'imperialistic' nature of the project, i.e. a model imported from the 'center' to be implemented in a 'periphery' nation, they have collaborated with their British counterparts to remodel their ELT curriculum to meet their own needs only. In this regard the local coordinator of the project states:

I am aware of this [linguistic imperialism]. In fact my colleagues in the department were also very concerned. But I think we've worked it out for ourselves. ... I think we will be getting all that we have stated in our proposal. The hardware, i.e. computers, the photocopier, and other equipment for the resources center are some of the major inputs that will be provided. It's a good bargain! That's how I would like to look at it. (Jacob, 1996: 3; cited in Holliday, 2005: 130-131)

\section{Business enterprises and private educational institutes}

In many countries business enterprises act as yet another major subnational force in influencing the government to borrow a policy from abroad. Bernard Spolsky (2004) considers business firms as strong players in language 
policy formation and argues that they often 'establish their own language policies' (Spolsky, 2004: 52). There are many reports of business enterprises expecting their staff to use a certain language at work. Examining language policy reform in Malaysia, Gill (2005) and David and Govindasamy (2005) present strong evidence as to how private business and industrial sectors have implicitly reversed Malaysian language policy in the direction they desired. As English grew as the dominant language of business and industry in the country, the Malaysian Employers Federation executive directors created a discourse calling for a need to restore English as the language of instruction at tertiary level, as a means of alleviating unemployment due to the lack of English language proficiency in college graduates. Although Malaysian business enterprises certainly did not have the power to make any decisions about policy formation, the discourse they created contributed to the government's decision in reversing the country's school language policies and, consequently, in looking abroad for a promising ELT model to emulate for the implementation of the new language policy.

In Iran, as will be illustrated in the following chapters, private language institutes have been the pioneers of the importation of ELT practices into the country. Unlike their counterparts in the secondary and post-secondary education system, private English language institutes which target fee-paying students (across all age and proficiency levels) are permitted to offer their own chosen curricula and textbooks as long as they comply with the numerous rules and regulations set by the state. In order to attract fee-paying students, private language institutes constantly look abroad for promising ELT models and textbooks to emulate. The borrowing process is accelerated due to the absence of a copyright convention for foreign-produced materials. This leap forward for the private sector has enabled it to participate - albeit indirectly and within a limited scale - in the educational decision-making process, in which the government has had a virtual monopoly (Borjian, 2010).

\section{Students, parents, teachers and other stakeholders}

To the list of subnational forces that may reinforce educational transfers, one may add students and their parents, whose contributions are often underestimated in academic research. As noted by John Hanson (1997), former director of the British Council, students and parents may have no interest in 'the health, future, spread, or whatever of the English language'. What interests them is a view of 'their job prospects, their relationship with the rest of the world, their excitement in youth culture, a wish to be insiders, to be in touch' (Hanson, 1997: 22; quoted in Pennycook, 2001: 57). Although Hanson's statement has been viewed as a normative claim and has triggered many 
counter-arguments by critical applied linguists (Pennycook, 2001; Phillipson, 1992), his statement shed light on another dimension of educational transfers the role of subnational forces and their various motives for foreign lessons and ideas.

Due to the high economic value associated with English, many parents push for English or English-medium schools merely to establish a better future for their children. In Kenya, for example, Bunyi (2005) states that many rural parents and students expressed the view that 'their children went to school to learn English but not their indigenous languages, which they already knew' (Bunyi, 2005: 131). In South Africa, parents believe that 'English puts bread on the table' and students think that 'English opens their brains' (Probyn, 2005: 153, 164). Thus there is a strong correlation between English and economic prosperity at an individual level, so economic motives could serve as a major impetus for students and parents to push for English education.

There are other motivations involved for parents and students, including English being the language of wider communication and of the global academic world. Faced with growing competition from English-medium private universities, Istanbul Technical University, the major Turkish state university, had no other alternative but to install English as the medium of instruction in more courses in order to attract students (Reagan \& Schreffler, 2005). There is a study on Iran (Riazi, 2005a) that shows how well-off families in Tehran are increasingly sending their children to private English tutorial schools to prepare them for a possible college-level education abroad, which the state-run schools with their locally produced curricula do not provide.

Subnational forces, like politicians, have their own motives and interests in promoting educational transfers. However, it is not true that local actors always push for the borrowing of a foreign model. On some occasions, they may even resist actions taken from elsewhere. Investigating educational language policy in Pakistan, Tariq Rahman (2005) casts light on how Pakistani religious groups, following the Islamic ulema, resisted the governmentimposed policy of the use of English as the language of instruction in religious schools (madrasas). The ulema felt that this demand for English, even in pragmatic terms, was really part of the state's project 'to colonize Islam'. The resistance of this powerful interest group led Pakistani politicians to modify their policy. This time they suggested English only as the alternative medium of instruction (the other one was Arabic). Another instance of resistance on the part of subnational forces could be the case of Sri Lanka. Due to the liberalization of its economy in the late 1980s, the Sri Lankan government sensed a need for a kind of interactive and productive English to boost the country's economy. With the support of the American Asia Foundation and the British Council, new curricula, emphasizing the importance of English 
for interpersonal communication, were designed and foreign textbooks were imported. The transferred education model was, however, rejected by local higher institutions such as Jaffna University. This resistance was due to the rise of linguistic nationalism among the Tamil community, who preferred to speak in their own mother tongue rather than what they called 'the language of the colonizer' (Canagarajah, 1999).

In short, subnational forces have their own motives and interests for educational transfers, quite apart from those of their politicians. However, it is important to consider the multiplicity of agencies among subnational forces when examining the borrowing process of ELT practices. As eloquently stated by Steiner-Khamsi and Stolpe (2006), neither are all actors in favor of educational import, nor are they all ready to execute the orders given from above or by their politicians.

\section{Supranational Forces and Educational Transfers}

In addition to domestic institutions and actors, international and transnational institutions and networks shape educational policies in many countries. In the preceding sections, we discussed the role of domestic actors, including national and subnational forces, in facilitating educational policy borrowing. In this section we will turn our focus to the other end of the spectrum, international and transnational organizations and networks, including multilateral and bilateral donors and INGOs, to illustrate their roles in boosting policy lending. In doing so, we will first define two different types of policy transfer, namely 'harmonization' and 'penetration'.

Harmonization, as defined by Bennett (1991), refers to a policy process in which policy borrowing is not made exclusively by the state, but rather by the existence of a cooperative relationship, at least nominally, among governmental, intergovernmental and international/foreign institutions. It is an obvious fact that states, as autonomous entities, have the authority to close their borders to any foreign influences they disapprove of, but in reality the constraints rooted in the international systems limit their exploits to a great extent. In reality, therefore, a government may agree, under pressure from supranational forces, to borrow or emulate a foreign lesson, idea or model and implement it locally.

Penetration, on the other hand, refers to a policy process in which states are compelled by external forces to copy actions taken from abroad. In some instances of policy penetration, even 'members of one polity serve as participants in the political processes of another' (Bennett, 1991: 227). Penetrative policies were, in fact, more common in the colonial era, when the colonizing 
countries were the absolute rulers and/or decision makers and participants in the political process of the subject nations. Nowadays, penetration has long been replaced by the more subtle and implicit process of harmonization. Nonetheless, penetrative policies have not fully faded away. Due to their desire to join the European Union (EU), Turkey and Latvia, for example, have explicitly been forced by other EU members to change their language policies. The former was required to stop repressing minority languages, especially Kurdish (Skutnabb-Kangas, 2006), whereas the latter was expected to respect minority language rights, including Russian, in education (Silova, 2004).

\section{International finance organizations}

Educational transfer through supranational forces lies above all in the role of the international finance organizations (multilateral donors operating between governments). International finance organizations have received different levels of attention. For some scholars, these organizations were created by the hegemonic power (such as the United States in the post-World War II period) to overcome the legacies of colonialism (McMichael, 1996; Phillipson, 1992; Wallerstein, 1979), and to establish order in the international system for its own benefit (Frank, 1966; Peet, 1999). Others view the emergence of international organizations as a response to the common needs of states seeking a prosperity and security which can be achieved through cooperation with other states (Keohane \& Nye, 1989). No matter how one may perceive international institutions, one cannot downplay the vital role they have played in reinforcing educational transfers.

One of the most important international finance institutions to shape education policies in developing nations is the World Bank. According to Jones (2004), the World Bank is not only in the business of disbursing loans but also of lending ideas, norms and education models. It is evident that low-income countries are profoundly dependent on international grants and loans and, consequently, on international financial organizations. Due to economic necessity, these nations are often left with no other choice but to accept the obligatory 'loan-conditionalities' which often include educational reforms. But how does the World Bank drive the import and export of ELT pedagogical practices?

The World Bank does not formally and explicitly impose an educational language policy on the borrowing countries; it maintains that each country must itself determine the language policy it deems best fitted to its peculiarities (Brock-Utne, 2001). Critical scholars, such as Alamin Mazrui (1997), remark, 'The same institution that has been coercing African governments into overhauling their educational structures virtually overnight has suddenly 
become mindful of the national sovereignty of these countries and of their right to linguistic self-determinism' (Mazrui, 1997: 3). What Mazrui is referring to (inconsistency between what the World Bank says and what it does on the ground) is an excellent instance of what we have labeled so far as the subtle process of 'harmonization'. The World Bank is not explicitly involved in other nations' educational policies, but what it does instead is the imposition of a package of conditions on the loan-receiving countries, in return for its loans.

One condition consists of pushing the aid-receiving nations to go along with the neoliberal economic policy of 'structural adjustment', i.e. encouraging private sector initiatives, reducing the presence of government and allowing market forces to operate (Vavrus, 2002). Structural adjustment often leads to the reduction of government subsidies for education. In Africa, for example, these subsidies are an indispensable source for the promotion of instruction in local African languages (Brock-Utne, 2001; Mazrui \& Mazrui, 1998). Without such subsidies, schools will not be able to produce learning materials and textbooks in local languages and, therefore, they will turn to ready-to-use materials and textbooks often donated by British governmental organizations and non-governmental organizations (NGOs). Such donations, as is argued by critical applied linguists (Canagarajah, 1999; Gray, 2002; Holliday, 1994; Phillipson, 1992), enable the center agencies to penetrate into the heart of periphery classrooms, not only by limiting the traditional role of the teachers as intellectuals but also by driving them 'to an attitude of dependence on the prepackaged, ready-to-use material freely provided by Western cultural agencies' (Canagarajah, 1999: 84-85).

Another result of the World Bank's structural adjustment policy is school privatization, allowing the private sector to manage schools. In Tanzania, for example, many of these private schools advertise themselves as English-medium schools and follow foreign-driven curricula and textbooks to attract fee-paying students because a high instrumental value is attached to English (Vavrus, 2002). As will be discussed in the following chapters, in Iran private language institutes have been the most active agents of the importation of ELT models into the country. However, it is hard to imagine the accomplishments of the private sector without the initiation of policy privatization by the country's politicians. By extension, the policymakers would not have implemented this policy privatization if the World Bank had not mandated such a policy implementation in return for the loans. Therefore, it would be misleading to view the private sector as entirely 'active agents', who voluntarily borrow ELT practices from abroad, without acknowledging the contribution of the World Bank to the overall borrowing-lending process (Borjian, 2010). 


\section{Bilateral donors}

Unlike the international finance organizations, bilateral donors are governmental entities dedicated to distributing aid within a government, e.g. the American USAID or the British DFID. The donations can be divided into two categories: humanitarian and developmental. The latter is intended to help other countries achieve long-term sustainable development. Some American and British bilateral donors use their funds to support the promotion of English language education and related teacher training and curriculum development projects in other countries. This can be seen in Uganda and Kenya (Mazrui \& Mazrui, 1998), Tanzania (Vavrus, 2002), Mongolia (Steiner-Khamsi \& Stolpe, 2006), Sri Lanka (Canagarajah, 1999), Syria, Pakistan (Holliday, 1994, 2005), and in India (Widdowson, 1999), among other nations.

Many donor agencies are involved in educational transfer, with varying goals and motives. In Africa, for example, some bilateral donor agencies, including the German DSE and GTZ and the Swiss Development Agency, along with UNESCO, are trying to support the development of African languages. These donors often accuse the World Bank of pouring its funds into the promotion of English and French, former colonial languages, rather than African ones (Brock-Utne, 2001). Therefore, the multiplicity of agencies among bilateral donors should be acknowledged.

\section{International non-governmental organizations}

As the term implies, INGOs are non-governmental in nature, as opposed to bilateral (operating within a government) or multilateral (operating between governments). Although most INGOs emphasize their non-governmental nature, some, like the British Council, have a close link to their government. As Canagarajah (1999) argues, the special potency of these INGOs in influencing periphery ELT enterprises 'lies in their ability to side-step the other macro-level periphery organizations (such as state agencies and educational bureaucracy) and reach directly into the language classrooms by supplying textbooks and by conducting teacher training courses' (Canagarajah, 1999: 84).

The involvement of INGOs in the borrowing and lending process of ELT practices might be either explicit or implicit. An explicit participation might be the role of the British Council, which has been thoroughly documented by Phillipson (1992), whereas an implicit example might be the American Asia Foundation, which theoretically should not have anything to do with ELT. In Sri Lanka, for example, the American Asia Foundation played a vital role, albeit indirectly, in disseminating CLT to Sri Lankan universities. This 
type of implicit support, as Canagarajah (1999) maintains, included sponsoring the visits of short- and long-term American consultants, establishing pre-sessional course for new entrants, holding annual teacher orientation seminars and donating books and equipment. Another example of an implicit involvement might be the case of the British Council in post-revolutionary Iran. Examining the limited domain of operation of the British Council in the country, Borjian (2011) argues that a regulation issued by Iranian politicians has prohibited the British Council from participating in teaching English in the country since the 1979 Islamic Revolution. The existence of this regulation, however, did not prevent the British Council from taking part in the country's English education while the British Council was permitted to operate in Iran, albeit in a limited scale, from 2001 to 2009. Targeting Iranian students and teachers, the British Council had a good track record of selling its English products, from textbooks to dictionaries to audio-video materials, to Iranian students, organizing teacher training workshops and getting a British scholarship for Iranian English teachers.

\section{International ELT professional networks}

The TESOL and applied linguistics professional associations and networks are the other types of INGOs which have been active participants in spreading ELT practices globally, through conferences, curriculum projects, publications, etc. ELT-related professional networks have received different levels of attention. For some scholars, such networks are inherently apolitical and their emergence is due to the existence of common needs among English teachers and practitioners to share ideas, expertise and information about ELT-related problems with their transnational counterparts. For others (Canagarajah, 1999; Holliday, 1994, 2005; Mazrui, 2004; Pennycook, 1989, 2001; Phillipson, 1992), such networks are interpreted as being the product of the American and British TESOL/applied linguistics centers in order to maintain their own power in the field of ELT. Some scholars go so far as to label these networks as agents of linguistic imperialism. Phillipson (1992) argues that the trajectory of TESOL/applied linguistics networks, as the dissemination of the 'global' language, involves a one-way flow of expert knowledge from the 'center' to the 'periphery'. Aligned with Phillipson, Holliday (1994) uses the term 'unilateral professionalism', arguing that ELT-related 'professionalism is ethnocentric' (Holliday, 1994: 3). Calling unilateral professionalism a type of imperialism, Holliday further argues that this imperialism works, not at the government level, but in the more piecemeal relations between native-speaker teachers, curriculum developers, project managers and trainers and their colleagues from the rest of the world. Looking through 
a similar lens, Canagarajah (1999) maintains that the dominance of center applied linguistics networks stems from their ability to conduct sophisticated research using hi-tech facilities and then to popularize this knowledge globally through their publishing networks and academic institutions. Whether one perceives such networks as 'apolitical' entities or as 'regimes' and/or 'agents of linguistic imperialism', one cannot deny the vital role they have played in transferring ELT practices around the world.

Having examined some of the agents and motives of educational transfer through external forces, we can argue that educational transfers via supranational forces are different from those initiated by domestic forces, both national and subnational. In this case, educational transfers are reinforced by strong institutional forces exogenous to a country and its political system. Although states as autonomous entities have the authority to close their borders to any foreign influences they disapprove of, as Iranian or Cuban politicians have done over the past several decades, in reality the advancement of technological communication, together with many constraints rooted in the international systems, limits their exploits to a great extent.

\section{Conclusion}

Drawing on the fields of comparative education, education policy studies and critical applied linguistics, we have examined a body of isolated studies to extract the most common variables associated with the process, causes and agents of ELT-related educational transfers worldwide. We proposed a threefold framework, each part of which related to different conditions of ELT educational transfers involving various actors and different causes.

Politicians and top governmental officials often play a vital role in reinforcing educational transfer. Having examined a body of ELT literature, we explored a number of reasons as to why politicians make references to lessons from elsewhere. Economic motives are a major reason for politicians to look abroad in search of a promising ELT package to emulate. This is in turn due to the fact that English has often been equated with economic growth and prosperity. We explored instances of such a cause for policy borrowing in Hong Kong, Singapore, Taiwan, the Philippines, Thailand and Malaysia. Another major set of motives for policy borrowing is political. Especially after a regime change, foreign-borrowed policies tend to reinforce the legitimization of the new regime and its ambitions for fundamental reform and, moreover, these policies seem to help the newly elected politicians to discredit their predecessors (Schriewer, 2004; Schriewer \& Martinez, 2004), as in the case of post-Soviet Russia. There is also a direct correspondence between policy bor- 
rowing and the domestic policy conflict. When a current practice becomes contested, politicians turn to externalized references in order to legitimize the need for reform at home (Luschei, 2004). We saw instances of such a policy in China. Yet politicians may have to borrow a model from abroad because of negative internal evaluations, as in the cases of Malaysia, Kenya and Uganda. Whatever the cause of policy borrowing, it tends to create conditions for politicians to search for successful examples of education models and standards elsewhere.

Subnational forces have their own motives and interests in education transfer, as they are not homogenous entities. ELT-related professional networks may use lesson drawing for the obvious reason that most problems have common solutions internationally. Their perception is frequently shaped through writing, speech-making and conferences, often organized, not to mention funded, by transnational organizations. There are societal actors who use external references to argue against policy decisions at home, as in the case of Iranian English teachers and professors. There are local actors who use the process as a pretext to meet their own needs, as we demonstrated in the case of English curriculum reform at Pune University in India. Local actors may also resist national and international forces, as in the cases of English professors in Sri Lanka and the ulema in Pakistan.

In addition to domestic institutions, ELT educational transfers in many countries are reinforced by foreign institutions. These exogenous forces include international finance organizations, bilateral donors and INGOs such as the British Council and ELT-related professional networks. There are instances where the assistance of the international donor indirectly promotes ELT practices, as exemplified by World Bank's structural adjustment policy. There are external forces which directly support the promotion of English and actively lend ELT practices to developing nations, as shown in Uganda, Kenya and Tanzania. INGOs and ELT-related professional networks have also played a significant role in lending English education models to other parts of the world, through numerous projects aimed at curriculum improvement and teacher training, among others. Although one should seriously take into account the role of external forces in reinforcing educational transfers, one should equally bear in mind that supranational forces cannot guarantee the implementation of an exported model in a local context. Rather, there must first be a need for borrowing, and secondly some mutual understanding between the lending nations/institutions and the borrowing ones. Otherwise, the borrowed policies would simply be ridiculed as being 'phony' or will be used as a mechanism by local stakeholders to meet their own needs. 